\title{
Measuring the level of social support using latent class analysis
}

\author{
Letícia Marques Santos $^{\mathrm{a}, *}$, Leila Denise A.F. Amorim ${ }^{\mathrm{b}}$, Darci Neves Santos ${ }^{\mathrm{a}}$, \\ Maurício L. Barreto ${ }^{\text {a }}$ \\ ${ }^{a}$ Instituto de Saúde Coletiva, Universidade Federal da Bahia, Rua Basílio da Gama, s/n, Campus Universitário, Canela, Salvador, Bahia 40110-040, Brazil \\ ${ }^{\mathrm{b}}$ Instituto de Matemática, Universidade Federal da Bahia, Rua Barão de Jeremoabo, s/n, Campus Universitário, Ondina, Salvador, Bahia 40170-115, Brazil
}

\section{A R T I C L E I N F O}

\section{Article history:}

Received 13 August 2013

Revised 12 November 2014

Accepted 18 November 2014

Available online 27 November 2014

\section{Keywords:}

Social support

Latent class analysis

Mental health

SSS-MOS

\begin{abstract}
A B S T R A C T
Different instruments have been used to measure social support in epidemiological studies of which the most widely used is the Medical Outcomes Study Social Support Scale (SSSMOS). However, these studies lack measures of the level of social support on health risks. We used latent class analysis (LCA) to distinguish subgroups with different levels of perceived social support and tested the consistency of these subgroups by their associations with the prevalence of Common Mental Disorders (CMD). This is a cross-sectional study of 1013 mothers living in the city of Salvador, Brazil in which psychosocial data were collected through home visits using the SSS-MOS and the Self Reporting Questionnaire-20. For each dimension of social support analysed here, we selected models with two classes using LCA. Multivariate logistic regression models were used to estimate the association between participants' perceived social support and the prevalence of CMD to verify the consistency of the groups defined by LCA. There was a clear difference in the reporting of perceived social support between those classified as high or low using LCA. The probability of perceiving several types of social support was lower in the subgroup classified as low level of social support (13.7-59.8\%), and it was much higher in the group classified as high level of social support (84.3-98\%). A greater prevalence of CMD was found among mothers with lower levels of social support. LCA seems to be a useful tool to improve measurement of perceived social support by separation into two levels in which the lower level is associated with an increased prevalence of CMD.
\end{abstract}

(c) 2014 Elsevier Inc. All rights reserved.

\section{Introduction}

Social support refers to the provision of psychological and material resources by a social network, aimed at improving an individual's ability to cope with stress (Cohen, 2004). It is an important predictor of physical and psychological health and well-being and plays a significant causal role in chronic non-communicable and infectious diseases, as well as in their treatment and rehabilitiation (Cohen and Syme, 1985; Cohen, 2004; Uchino et al., 2012). Social support is also associated with reductions in cancer mortality rates (Pinquart and Duberstein, 2010), a reduced risk of coronary heart disease (Uchino et al., 1996), improved prognosis and survival for cardiovascular and brain diseases (Berkman and Glass, 2000), protection

\footnotetext{
* Corresponding author. Fax: +55 7133360695.

E-mail addresses: marquesleticia@hotmail.com (L.M. Santos), leiladen@ufba.br (L.D.A.F. Amorim), darci@ufba.br (D.N. Santos), mauricio@ufba.br (M.L. Barreto).
} 
against depression and anxiety (Kawachi and Berkman, 2001; Stansfeld, 2002; Cohen, 2004), and an improved ability to cope with stress resulting from chronic illness (Stansfeld, 2002).

There is evidence that social support and social ties benefit an individual's mental health and psychological well-being (Turner and Marino, 1994; Kawachi and Berkman, 2001). Several studies have emphasized the effect of social support on reducing the symptoms of depression, anxiety, social phobia, and Common Mental Disorders (CMD) (Costa and Ludemir, 2005; Maulik et al., 2009; Moak and Agrawal, 2009; Kim, 2010). The positive effects of social support on mental health may be observed at any age, independent of the source that provides it, as long as the individual perceives him/herself to be socially integrated and supported (Cornwell and Waite, 2009a).

Over the years, increasing efforts have been made to achieve better measures of social support, disentangling a set of dimensions, which include informational support, tangible help, emotional support and integration (Krause and Markides, 1990), social disconnectedness and perceived isolation (Cornwell and Waite, 2009b), and social health (Cella et al., 2007). However, debate about the quality of instruments that measure social support is minimal (Uchino et al., 1996; Gonçalves et al., 2011). Few studies have analysed the quality of social support measures used in survey research (Sherbourne and Stewart, 1991; Berkman and Glass, 2000; Griep et al., 2005; Gonçalves et al., 2011; Uchino et al., 2012) and when such studies have been conducted, analysis has been restricted to an evaluation of the instrument's dimensionality, and occasionally to aspects related to construct validity (Sherbourne and Stewart, 1991; Griep et al., 2005; Gonçalves et al., 2011).

Furthermore, studies do not adequately respond to issues related to the choice of cut-off points in quantitative scales with different levels of risks for health or behavioural outcomes (Uchino et al., 1996; Gonçalves et al., 2011). This hampers recognition of specific characteristics of any given subgroup that could be at a greater risk of health problems (Corin, 1994). A more refined analysis of social support measures is necessary to improve recognition of their impact on health.

One of the most widely used instruments in epidemiological research is the perceived social support scale (SSS-MOS) developed for the Medical Outcomes Study (Sherbourne and Stewart, 1991; Berkman and Glass, 2000; Griep et al., 2005). This scale was constructed at the end of the 1980s and was designed to cover five dimensions of social support, such as emotional support (expressions of positive affect, empathy, care and trust); affective support (expressions of love and affection); material support (provision of material help); informational support (provision of information that helps the individual to deal with difficulties); and positive social interaction (the availability of company for leisure activities) (Sherbourne and Stewart, 1991).

The scale is considered an adequate measure of perceived social support (Berkman and Glass, 2000), and it has been adapted and validated for the Brazilian population (Griep et al., 2005). Several studies on the SSS-MOS conducted in different countries (Sherbourne and Stewart, 1991; Mahmud et al., 2004; Griep et al., 2005; Espínola et al., 2007; Robitaille et al., 2011) focus on presenting its psychometric properties, but nobody has yet used it to provide a clear definition for cut-off points in the original scale for the identification of levels of perceived social support associated with different risks to mental or physical health. Instead of choosing a cut-off point for the sum of responses for each item, some studies use a continuous score to represent social support (Aflakseir, 2010), while others classify scores below the median (Griep et al., 2005) or the first tertile (Andrade et al., 2005; Pinto et al., 2006) as representative of a low level of perceived social support. There are also studies that merely provide the chosen score for cut-off - 75 points (Hasselmann et al., 2008), 57 points (Salinero-Fort et al., 2011), 33 points (Costa and Ludemir, 2005) - with no explanation about how the authors reached these scores or what they represent. Thus, the criteria for classifying the scores of the SSS-MOS and characterizing levels of perceived social support seems to be somewhat arbitrary.

From this perspective, latent class analysis (LCA) is a useful statistical technique for clustering individuals into subtypes within a population when there is no prior knowledge about which individual belongs to which subpopulation. This method is used to analyse multivariate categorical data and model associations between observed variables that provide an imperfect measure of a non-observable (latent) variable. The discrimination of subgroups (also called classes) arises from an evaluation of response patterns and the probabilities associated with each of the observed variables. This allows us, for example, to identify a group of subjects with a high probability of reporting low levels of social support, according to their responses to items on a scale (Collins and Lanza, 2010).

LCA is increasingly used in public health studies to identify metabolic syndrome (Boyko et al., 2012), immunological patterns (Figueiredo et al., 2013) and incidence of respiratory symptoms in children (Spycher et al., 2008), and has proven to be an efficient method for disentangling groups and creating more homogeneous subgroups. In relation to instrument consistency, LCA has been used to identify the subtypes of Antisocial Personality Disorder (Bucholz et al., 2000), Attention Deficit/ Hyperactivity Disorder (Rasmussen et al., 2002), and patterns of problem behaviour (Lang et al., 2006). These studies aim to improve diagnostic validity by relying on empirical evidence, and moving towards more valid and useful classification criteria.

Working with a large sample of women to whom the Medical Outcomes Study Social Support Scale was applied, this study aims to distinguish subgroups with different levels of perceived social support by using the LCA technique. We also seek to analyze the agreement between the classifications as defined by an analysis of response patterns using LCA, compared to that obtained using the median as a cut-off point of the original score, as used by many investigators. Finally, we test whether the different levels of perceived social support identified here are associated with prevalence of Common Mental Disorders (CMD). 


\section{Methods}

\subsection{Study design and participants}

This is a cross-sectional study of 1013 mothers of children aged between 4 and 12 years old, part of a population cohort in the city of Salvador. Participants were randomly selected from a set of 20,000 residences within the city of varying economic levels and environmental conditions, organized into 24 geographic areas (Barreto et al., 2006). Of the 1445 families initially recruited for the study, 259 were excluded because a guardian who was not the child's biological mother answered their psychosocial questionnaires. Moreover, it was not possible to locate 55 families due to changes of address, while 118 questionnaires lacked sufficient data, leaving 1013 mothers to form the sample used in this work. As this work is part of a series of previous publications (Barreto et al., 2006), to maintain consistency in the subpopulation studied in the project, we only selected the mother's dataset, on the assumption that the mother's characteristics have a strong influence on the child's health status.

\subsection{The Medical Outcomes Study Social Support Scale}

This scale is composed of 19 items with positive descriptions and responses on a five-point scale, where $1=$ never, $2=$ rarely, $3=$ sometimes, $4=$ almost always and $5=$ always, to identify the frequency with which social support is perceived (Sherbourne and Stewart, 1991). The score was calculated for each dimension through the sum of points attributed to the items divided by the highest possible score for each dimension. To standardize the score of social support scale, the results of the ratio (total points obtained/high score for the dimension) were multiplied by 100 .

The scale has been adapted and validated in Brazil and presents high internal consistency levels and moderate item-scale correlation, enabling it to be used as a measure of perceived social support (Griep et al., 2005). Although the original scale was designed to cover five social support dimensions, only three dimensions have been identified in the Brazilian population: positive social interaction/affective support; emotional/information support; and material support (Griep et al., 2005).

Given these differences, we decided to identify scale dimensionality using exploratory factor analysis with the principal axis method for the extraction of factors and varimax orthogonal rotation. Following another Brazilian study (Griep et al., 2005), the items were grouped according to the three factors identified in our study: (1) Affective support and positive social interaction, including all the items of these sub-scales and adding an item from the emotional support sub-scale (someone who understands your problems); (2) Emotional and informational support, which involved all the questions from both subscales, except the one included in the first factor; and (3) Material support, for which we maintained the four items from the original scale. The goodness of fit indices demonstrated the adequacy of analysed data (KMO $=.953$; Bartlett's test of sphericity with a $\mathrm{p}$ value $=.000$ ).

\subsection{Instruments used to identify LCA group consistency}

The Self Reporting Questionnaire (SRQ-20) was used to identify mothers with suspected Common Mental Disorders (CMD). This inventory was developed by the World Health Organization and has been validated for the Brazilian population (Mari and Williams, 1986; Gonçalves et al., 2008). It is composed of 20 dichotomous (Yes/No) questions which enquire about the presence or absence of symptoms suggestive of the following disorders: depression; dysthymia; phobia/anxiety; somatisation and neurasthenia. Compared to the diagnostic psychiatric interview, Brazilian studies revealed high sensitivity (85\%) and specificity $(80 \%)$ for this instrument, and indicated that a cut-off point of 8 or more symptoms could be used to identify participants with suspected CMDs (Mari and Williams, 1986; Gonçalves et al., 2008).

\subsection{Statistical analyses}

LCA is one of the most widely used latent class models for categorical data and serves to cluster individuals into mutually exclusive classes that represent groups of individuals who are similar to each other, based on a set of observed categorical variables. The model estimates the smallest number of groups (latent classes) that describe the variability of response patterns within the population. Model interpretation is based on the estimated probabilities of membership of each class (class prevalence) and on the probabilities of a given response for the observed variables conditional on the class to which he/she belongs. Interpretation of the classes is carried out by comparing the probability of each response in each class relative to the overall population (Collins and Lanza, 2010).

The evaluation of the model's goodness of fit was achieved through entropy and the G-Lo-Mendell-Rubin likelihood ratio test (Collins and Lanza, 2010). The entropy index measures the quality of the resulting classification in terms of the separation of the latent classes. Its values range from 0 to 1 , where high values $(>0.90)$ indicate that the latent classes are highly discriminative.

In order to fit the latent variable models, the instrument items were organized according to the dimensions identified in the exploratory factor analysis. The responses were then dichotomized so that the response options "never", "rarely" and "sometimes" formed a new category indicative of a lower perception of social support; while the options "almost always" 
and "always" formed another category which was indicative of a higher perception of social support. This re-arrangement was important in providing response categories with frequencies higher than $10 \%$ and improved our capacity to interpret the LCA findings. The frequency of answers "never", "rarely" and "sometimes" varied between 46.1\% and 20.8\%, which demonstrates that most answers were "almost always" and "always" options.

For each of the three dimensions of social support, we selected models with two latent classes. We used the same methodology to estimate the subgroups for the global social support scale. Conditional probabilities are presented for the final models; these are the probabilities of reporting specific social support items conditional on membership of that particular latent class (denoting level of perceived social support). These analyses were implemented using Mplus version 5 software (Muthèn and Muthèn, 1998-2007). Estimation in MPlus is obtained via the EM algorithm.

Furthermore, we used the original score from the social support scale to compute its median. Scoring below or above the median of the original scores on the scale is referred to in the literature as a cut-off point to classify individuals into low and high level social support groups. The Kappa index was used to measure agreement between the two different forms of classification based on the medians of the original scores and on the groups discriminated by LCA.

The consistency of the social support subgroups was also evaluated using multivariate logistic regression analysis to estimate the association between social support and CMD prevalence, adjusting for socio-demographic indicators, such as income, schooling, child's age, paved roads, piped water and access to the sewerage system. Odds ratios (ORs) and corresponding 95\% confidence intervals were provided using STATA software program version 10.0.

\subsection{Ethical considerations}

The study was approved in 2005 by the National Ethics Committee, under registration number 047-05/CEP-ISC FR-78168. Participants signed a Free and Informed Consent Form, which contained detailed information about the data collection procedures for the research. Participants were informed of any results that suggested a need for medical/psychological care and were provided with relevant information about the health service.

\section{Results}

\subsection{Sample description}

The participants' average age was 32.2 years (SD 6.73), most had only one child (58.1\%), were of mixed race (66.6\%), had not completed secondary education (69.9\%) and had an income of less than one minimum wage per month (54.3\%). There were $9.1 \%$ of participants living without piped water, $16.9 \%$ did not have access to the sewerage system and $64.8 \%$ did not have access to paved roads. The prevalence of suspected CMD was $37.7 \%$.

\section{2. $L C A$ results}

For the material support dimension, we observed that, among the participants classified as having high social support levels, the probability of perceiving this type of support in any of the items ranged from $85.6 \%$ to $93.6 \%$. On the other hand, amongst those who demonstrated less perception of material support, the probability of such support ranged from $17.3 \%$ to 46.4\% (Table 1).

A similar pattern was observed for the emotional and informational support sub-scales, where the probability of perceiving this type of support amongst participants classified with high levels ranged from $87.4 \%$ to $92.8 \%$. On the other hand, for those classified as having lower perceptions of social support, there was a lower probability of such responses (from $20.3 \%$ to 43.7\%). Furthermore, for the items that made up the dimension of affective support and positive social interaction, the probability of referring to this type of support ranged from $87.1 \%$ to $98 \%$ and from $20 \%$ to $59.8 \%$, amongst women classified in the profiles of higher and lower perceptions of support, respectively (Table 1 ).

We observed the same pattern in the global social support analysis. We identified higher probabilities of perceiving social support amongst participants classified with high levels of global social support. These probabilities ranged from $87.2 \%$ to 98.4\%. On the other hand, for those classified as having lower levels of global social support, the probabilities of perceiving social support were lower, ranging from $25.5 \%$ to $67.9 \%$.

Despite the majority of participants being classified as perceiving high levels of social support, groups of women with both low and high levels of social support, were characterised for all dimensions analyzed. The entropy values for the three types of identified support and for the global social support scale were above 0.732 , indicating adequate goodness of fit (Table 2).

\subsection{Results of the evaluation of social support profile consistency}

The results of the analysis of agreement between subgroups created by LCA and those created using the median as cut-off point are presented in Table 3. We observed that $100 \%$ of the participants classified as having a low level of social support using LCA were also classified as having a low level of social support using the median as a cut-off point, for each dimension 
Table 1

Description of levels of perceived social support using latent class analysis, according to three dimensions of support (material, emotional and information, and affective and positive social interaction) $(N=1013)$.

\begin{tabular}{|c|c|c|c|}
\hline & Overall $N(\%)$ & High (\%) & Low $(\%)$ \\
\hline \multicolumn{4}{|l|}{ Material social support } \\
\hline \multicolumn{4}{|l|}{ Availability of someone to: } \\
\hline Help if confined to bed & $765(75.5)$ & 91.4 & 46.4 \\
\hline Take to doctor & $678(66.9)$ & 85.6 & 32.6 \\
\hline Prepare meals & $636(62.8)$ & 87.5 & 17.3 \\
\hline Help with daily chores & $710(70.1)$ & 93.6 & 27.0 \\
\hline \multicolumn{4}{|l|}{ Emotional and informational social support } \\
\hline \multicolumn{4}{|l|}{ Availability of someone to: } \\
\hline Listen to you & $730(72.1)$ & 91.3 & 41.7 \\
\hline Give you good advice & $747(73.7)$ & 92.8 & 43.7 \\
\hline Give you information & $705(69.6)$ & 91.1 & 35.7 \\
\hline Confide in & $710(70.1)$ & 92.0 & 35.5 \\
\hline Give advice you really want & $698(68.9)$ & 92.5 & 31.7 \\
\hline Share worries with & $624(61.6)$ & 87.4 & 20.9 \\
\hline Turn to for suggestions & $650(64.2)$ & 92.0 & 20.3 \\
\hline \multicolumn{4}{|l|}{ Positive social interaction and affective support } \\
\hline \multicolumn{4}{|c|}{ Availability of someone to: } \\
\hline Show love and affection & $865(85.4)$ & 98.0 & 59.8 \\
\hline Have good time with & $723(71.4)$ & 87.8 & 38.1 \\
\hline Hug you & 789 (77.9) & 92.5 & 48.2 \\
\hline Get together for relaxation & $671(66.2)$ & 87.1 & 23.9 \\
\hline Help you to get your mind off things & $702(69.3)$ & 89.3 & 28.6 \\
\hline Do something enjoyable with & $693(68.4)$ & 91.4 & 21.7 \\
\hline Understand your problems & $639(63.1)$ & 84.3 & 20.0 \\
\hline Love you & 809 (79.9) & 94.9 & 49.3 \\
\hline
\end{tabular}

Table 2

Social support latent classes for different dimensions of perceived social support $(N=1013)$.

\begin{tabular}{llll}
\hline Social support latent classes & $N$ & $\%$ & Entropy $^{*}$ \\
\hline Material social support & & 65.8 \\
$\quad$ High & 667 & 34.2 \\
$\quad$ Low & 346 & 61.9 \\
Emotional and information social support & 627 & 38.1 & 0.858 \\
$\quad$ High & 386 & 66.2 \\
Low & 671 & 33.8 \\
Affective social support and positive social interaction & 342 & 57.3 \\
$\quad$ High & 581 & 42.7 \\
Low & 433 & 0.844 \\
Global social support & & 0.925 \\
High & & \\
\hline
\end{tabular}

* Model fit index.

Table 3

Levels of agreement between the subgroups of social support, classified according to LCA technique and using the median as cut-off point $(N=1013)$.

\begin{tabular}{|c|c|c|c|c|}
\hline \multirow{2}{*}{$\begin{array}{l}\text { Subgroups created using LCA technique } \\
\text { Material support }\end{array}$} & \multicolumn{2}{|c|}{ Subgroups created using median as cut-off point } & \multirow{2}{*}{$\frac{\text { Overall\% of agreement }}{83.6}$} & \multirow{2}{*}{$\begin{array}{c}\text { Kappa } \\
0.67^{*}\end{array}$} \\
\hline & $\operatorname{High} N(\%)$ & Low $N(\%)$ & & \\
\hline High & $501(75.1)$ & $166(24.9)$ & & \\
\hline Low & 0 & $346(100)$ & & \\
\hline Emotional and informational support & High $N(\%)$ & Low $N(\%)$ & 90.9 & $0.82^{*}$ \\
\hline High & $535(85.3)$ & $92(14.7)$ & & \\
\hline Low & 0 & $386(100)$ & & \\
\hline Positive social interaction and affective support & High $N(\%)$ & Low $N(\%)$ & 78.4 & $0.58^{*}$ \\
\hline High & $452(67.4)$ & $219(32.6)$ & & \\
\hline Low & 0 & $342(100)$ & & \\
\hline Global social support & High $N(\%)$ & Low $N(\%)$ & 90.2 & $0.81^{*}$ \\
\hline High & $491(98.2)$ & $90(17.5)$ & & \\
\hline Low & $9(1.8)$ & $423(82.5)$ & & \\
\hline
\end{tabular}

${ }^{*} p<0.001$. 
Table 4

Crude and adjusted associations between participant perceived social support level as identified by LCA and suspected Common Mental Disorder (CMD) $(N=1013)$.

\begin{tabular}{|c|c|c|c|}
\hline Variables & $\begin{array}{l}\text { CMD } \\
\text { Suspected } N(\%)\end{array}$ & OR crude (CI95\%) & OR $\operatorname{adj}^{*}(\mathrm{CI} 95 \%)$ \\
\hline \multicolumn{4}{|c|}{ Material support } \\
\hline High & $233(34.9)$ & 1.00 & 1.00 \\
\hline Low & $149(43.1)$ & $1.41(1.08-1.84)$ & $1.38(1.06-1.81)$ \\
\hline \multicolumn{4}{|c|}{ Emotional and informational support } \\
\hline High & $205(32.7)$ & 1.00 & 1.00 \\
\hline Low & $177(45.8)$ & $1.74(1.34-2.26)$ & $1.77(1.35-2.31)$ \\
\hline \multicolumn{4}{|c|}{ Positive social interaction and affective support } \\
\hline High & $219(32.6)$ & 1.00 & 1.00 \\
\hline Low & $163(47.7)$ & $1.88(1.44-2.45)$ & $1.85(1.41-2.43)$ \\
\hline \multicolumn{4}{|c|}{ Global social support } \\
\hline High & $187(32.2)$ & 1.00 & 1.00 \\
\hline Low & $195(45.1)$ & $1.73(1.34-2.24)$ & $1.73(1.33-2.26)$ \\
\hline
\end{tabular}

OR adjusted for income, schooling, age of the children, paved roads, piped water and access to the sewerage system.

analyzed separately. However, $1.8 \%$ of the participants classified as having a low level of global social support using LCA were classified as having a high level of social support using the median as a cut-off point.

The agreement in the subgroups of higher levels of social support was smaller compared to agreement in the lower levels of social support, although most participants were equally classified using both techniques for all dimensions. Nevertheless, the overall percentage of agreement was high for all dimensions, varying between $78.4 \%$ for positive social interaction and affective support, to $90.9 \%$ for emotional and informational support. Generally, Kappa values were statistically significant and indicated substantial agreement, except for positive social interaction and affective support, where the Kappa indicated moderate agreement (Table 3).

We also observed that those participants classified as having lower levels of social support across all dimensions had a greater chance of presenting CMD, compared to those classified as having higher levels of support. This increased chance of CMD ranged from $38 \%$, for those with lower perceptions of material support, to $86 \%$ for those with lower levels of affective support and positive social interaction. (Table 4).

\section{Discussion}

This paper presents an application of the LCA technique for the classification of groups according to perceived levels of social support in order to identify more accurate levels of social support, which represents risks to health. Two groups of high and low social support, respectively, were identified for all the three dimensions of social support investigated. There was a clear pattern in the probability of reporting social support stated in the two subgroups; a lower probability of reporting in the group labelled low level of social support, and a much higher one for the subgroup characterised with a high level of social support. Further, higher prevalence of CMD was observed amongst those participants with low levels of social support, as identified by LCA.

The application of LCA to distinguish levels of social support goes beyond other techniques because it precisely identifies the contribution of each indicator to the frame of the subgroups created. This means that, in addition to classifying the individuals according to the level of social support, one can identify the array of observed variables that represent each dimension of social support and characterize what is called high or low level of social support (Collins and Lanza, 2010).

Although we cannot discard the use of any variable-based method (as median) to define the level of response to SSS-MOS, based on our findings, we strongly recommend the use of the LCA technique to identify patterns of social support perception. This technique enables one to have precise and theory-based classes of social support extracted from SSS-MOS. This is especially relevant because social support is a complex construct that cannot be directly observed and has potentially different effects on health (Berkman and Glass, 2000; Kawachi and Berkman, 2001; Stansfeld, 2002). There is evidence that material and informational support can have a strong effect on individual physical health, since it can improve the access to resource and tangible aids (Berkman and Glass, 2000). On the other hand, emotional support may help the individual to deal effectively with stressful situations, preventing a cascade of negative emotional and behavioural responses, and the subsequent repercussions on individual psychological status and mental health (Kawachi and Berkman, 2001).

Investigators are increasingly using latent class analysis as an improved approach to identify underlying subgroups of individuals who share important characteristics and behaviours (Bucholz et al., 2000; Rasmussen et al., 2002; Lang et al., 2006). When using categorical data in this approach, one advantage is not have to make assumptions about the distributions of indicators, except in relation to local independence; in other words, there is an assumption that within a latent class the indicators are independent. This approach may be useful not only when data can only be captured categorically, but also may qualitatively describe how the groups are different, based on their responses. 
However, there are limitations to using LCA arising from sample size requirements. LCA requires a sufficient sample size because of sparse cells, or small cell counts in the contingency table, which may lead to unstable results (Collins and Lanza, 2010). This is one reason for our decision to dichotomize the variables for each item on the social support scale. In order to consider the five categories of each item, a larger sample size is required to avoid unreliable results. The model's results focus on a description of estimated probabilities and one major aspect of an assessment of the model fit is whether the model is supported by related theory and whether the classes may be interpreted as meaningful. A model should not only be selected because it fits the data according to a certain statistical criterion, but due to the interpretability of the parameters, which is related to model plausibility.

To our knowledge, this is the first study of its type, which is why we verified the consistency of the social support groups created using LCA. We found general agreement between the classification created by LCA and that using the median as cutoff point for the original score. Furthermore, for all the social support dimensions analysed, participants with lower social support levels presented a higher prevalence of CMD, corroborating other studies that have reinforced the relationship between social integration and mental health (Kawachi and Berkman, 2001; Costa and Ludemir, 2005; Cornwell and Waite, 2009; Moak and Agrawal, 2009; Kim, 2010). Although we cannot generalize these results beyond the mental health domain, this method may be useful for other health domains (i.e. physical health) not tested in the current study.

We should emphasize that social support is transactional in nature; it involves reciprocity and is constructed over the life course. Not all social ties are supportive, and even with those that are, the support offered varies in type, frequency and intensity (Berkman et al., 2000; Stansfeld, 2002). So, contexts reflecting diverse life course stages, socioeconomic status and culture may therefore affect the thresholds found in our study, which limits our findings.

Another limitation refers to the cross-sectional nature of the design, which does not allow us to confirm the temporality of the relationships established here. However, our study did not seek to identify determinant factors for CMD; the estimated associations were relevant for a verification of the consistency of the subgroups distinguished by LCA and defining different levels of social support. Further, despite the use of validated questionnaires it is known that measurements of social support and mental health may be subject to respondent bias, since anxious or depressed individuals, with low incomes and with less access to social and health services tend to treat reality with less optimism and probably also perceive the level of social support around him/her lower than effectively it is (Kawachi and Berkman, 2001; Stansfeld, 2002).

The application of LCA in our work provides a useful identification and characterization of different levels of social support, allowing this population to be described according to a level of social support that may represent health risks. The refinement of social support measurements achieved here provides a better understanding of the social determinants of health, as well as theoretical underpinnings for the formulation of health care policies, enabling a new approach to the health/disease/care process. From the health promotion point of view, it enables one to identify groups exposed to low levels of social support and thus direct policy-related efforts to improving the social ties of such groups, ameliorating their state of health, including common mental disorders.

\section{Acknowledgments}

To Conselho Nacional de Desenvolvimento Científico e Tecnológico (CNPq) for a Postdoctoral scholarship to the first author.

\section{Appendix A. Supplementary material}

Supplementary data associated with this article can be found, in the online version, at http://dx.doi.org/10.1016/ j.ssresearch.2014.11.009.

\section{References}

Aflakseir, A., 2010. The role of social support and coping strategies on mental health of a group of Iranian disabled war veterans. Iran. J. Psychiatr. 5 (3), $102-$ 107.

Andrade, C.R., Chor, D., Faerstein, E., Griep, R.H., Lopes, C.S., Fonseca, M., 2005. Apoio social e auto-exame das mamas no Estudo Pró-Saúde. Cadernos de Saúde Pública 21, 379-386.

Barreto, M.L., Cunha, S.S., Alcântara-Neves, N., Carvalho, L.P., Cruz, A.A., Stein, R.R., Rodrigues, L.C., 2006. Risk factors and immunological pathways for asthma and other allergic diseases in children: background and methodology of a longitudinal study in a large urban centre in Northeastern Brazil (Salvador-SCAALA study). BMC Pulm. Med. 23, 6-15.

Berkman, L.F., Glass, T., 2000. Social integration, social networks, social support, and health. In: Berkman, L.F., Kawachi, I. (Eds.), Social Epidemiology. Oxford Press, Oxford, UK, pp. 137-173.

Berkman, L.F., Glass, T., Brissette, I., Seeman, T.E., 2000. From social integration to health: Durkheim in the new millennium. Soc. Sci. Med. 51 , $843-857$.

Boyko, E.J., Doheny, R.A., McNeely, M., Kahn, S., Leonetti, D.L., Fujimoto, W.Y., 2012. Latent class analysis of the metabolic syndrome. Diabetes Res. Clin. Pract. $89,88-93$.

Bucholz, K.K., Hesselbrock, V.M., Heath, A.C., Kramer, J.R., Schuckit, M.A., 2000. A latent class analysis of antisocial personality disorder symptom data from a multi-centre family study of alcoholism. Addiction 95 (4), 553-567.

Cella, D., Yount, S., Rothrock, N., Gershon, R., Cook, K., Reeve, B., Rose, M., 2007. The Patient-Reported Outcomes Measurement Information System (PROMIS): progress of an NIH Roadmap cooperative group during its first two years. Med. Care 45 (5 Suppl 1), S3-S11.

Cohen, S., 2004. Social relationships and health. Am. Psychol. 59 (8), 676-684.

Cohen, S., Syme, S.L., 1985. Issues in the study and application of social support. In: Cohen, S., Syme, S.L. (Eds.), Social Support and Health. Academic Press, San Francisco, USA, pp. 3-22. 
Collins, L.M., Lanza, S.T., 2010. Latent Class and Latent Transition Analysis with Applications in the Social, Behavioural, and Health Sciences. Wiley, New Jersey, USA.

Corin, E., 1994. The social and cultural matrix of health and disease. In: Evas, R.G., Barer, M.L., Marmot, T.R. (Eds.), Why Are Some People Healthy and Others Not? The Determinants of Health of Populations. Aldine de Gruyter, New York, pp. 93-132.

Cornwell, E.Y., Waite, L.J., 2009a. Social disconnectedness, perceived isolation, and health among older adults. J. Health Soc. Behav. 50 , $31-48$.

Cornwell, E.Y., Waite, L.J., 2009b. Measuring social isolation among older adults using multiple indicators from the NSHAP Study. J. Gerontol. B Psychol. Sci. Soc. Sci. 64 (Suppl 1), i38-i46.

Costa, A.G., Ludemir, A.B., 2005. Transtornos mentais comuns e apoio social: estudo em comunidade rural da Zona da Mata de Pernambuco, Brasil. Cadernos de Saúde Pública 21 (1), 73-79.

Espínola, R., Enrique, S., Carmelo, H., 2007. Validación argentina del cuestionario MOS de apoyo social percibido. Psicodebate: Psicología, Cultura y Sociedad 7, 155-168.

Figueiredo, C.A., Amorim, L.D., Alcântara-Neves, N.M., Matos, S.M.A., Cooper, P.J., Rodrigues, L.C., Barreto, M.L., 2013. Environmental conditions, immunological phenotypes, atopy and asthma: new evidence of how hygiene hypothesis operates in Latin America. J. Aller. Clin. Immunol. 131 (4), 1064-1068.

Gonçalves, T.R., Pawlowski, J., Bandeira, D.R., Piccinini, C.A., 2011. Avaliação de apoio social em estudos brasileiros: aspectos conceituais e instrumentos. Ciência and Saúde Coletiva 16 (3), 1755-1769.

Gonçalves, D.M., Stein, A.T., Kapczinski, F., 2008. Performance of the self-reporting questionnaire as a psychiatric screening questionnaire: a comparative study with structured clinical interview for DSM-IV-TR. Cadernos de Saúde Pública 24 (2), 380-390.

Griep, R.H., Chor, D., Faerstein, E., Werneck, G.L., Lopes, C.S., 2005. Validade de constructo de escala de apoio social do Medical Outcomes Study adaptada para o português no Estudo Pró-Saúde. Cadernos de Saúde Pública 21 (3), 703-714.

Hasselmann, M.H., Werneck, G.L., Silva, C.V.C., 2008. Symptoms of postpartum depression and early interruption of exclusive breastfeeding in the first two months of life. Cadernos de Saúde Pública 24 (Suppl. 2), S341-S352.

Kawachi, I., Berkman, L.F., 2001. Social ties and mental health. J. Urban Health 78 (3), 458-467.

Kim, J., 2010. Neighborhood disadvantage and mental health: the role of neighborhood disorder and social relationships. Soc. Sci. Res. 39 (2), $260-271$.

Krause, N., Markides, K., 1990. Measuring social support among older adults. Int. J. Aging Human Develop. 30 (1), $37-53$.

Lang, N.D.J., Ferdinand, R.F., Ormel, J., Verhulsta, F.C., 2006. Latent class analysis of anxiety and depressive symptoms of the Youth Self-Report in a general population sample of young adolescents. Behav. Res. Ther. 44, 849-860.

Mahmud, W., Awang, A., Mohamed, M.N., 2004. Psychometric evaluation of the Medical Outcome Study (MOS) social support survey among Malay postpartum women in Kedah, North West of Peninsular Malaysia. Malay. J. Med. Sci. 11 (2), 26-33.

Mari, J.J., Williams, P., 1986. A validity study of a psychiatric screening questionnaire (SRQ-20) in primary care in the city of São Paulo. Br. J. Psychiatr. 48, $23-26$.

Maulik, P.K., Eaton, W.W., Bradshaw, C.P., 2009. The role of social network and support in mental health service use: findings from the Baltimore ECA study. Psychiatr. Serv. 60 (9), 1222-1229.

Moak, Z.B., Agrawal, A., 2009. The association between perceived interpersonal social support and physical and mental health: results from the national epidemiological survey on alcohol and related conditions. J. Public Health 32 (2), 191-201.

Muthèn, L.K., Muthèn, B.O., 1998-2007. MPlus Useŕs Guide, fifth ed., Los Angeles, CA: Muthèn \& Muthèn.

Pinquart, M., Duberstein, P.R., 2010. Associations of social networks with cancer mortality: A meta-analysis. Crit. Rev. Oncol./Hematol. 75, 122-137.

Pinto, J.L., Garcia, A.C., Bocchi, S.C., Carvalhães, M.A., 2006. Características do apoio social oferecido a idosos de área rural assistida pelo PSF. Ciência and Saúde Coletiva 2006 (11), 753-764.

Rasmussen, E.R., Todd, R.D., Neuman, R.J., Heath, A.C., Reich, W., Rohde, L.A., 2002. Comparison of male adolescent-report of attention deficit/hyperactivity disorder (ADHD) symptoms across two cultures using latent class and principal components analysis. J. Child Psychol. Psychiatr. 43 (6), $797-805$.

Robitaille, A., Orpana, H., McIntosh, C.N., 2011. Psychometric properties, factorial structure, and measurement invariance of the English and French versions of the Medical Outcomes Study social support scale. Health Rep. 22 (2), 1-8.

Salinero-Fort, M.A., Otero-Sanz, L., Martín-Madrazo, C., Burgos-Lunar, C., Chico-Moraleja, R.M., Rodés-Soldevila, B., Gómez-Campelo, P., 2011. The relationship between social support and self reported health status in immigrants: an adjusted analysis in the Madrid Cross Sectional Study. BMC Family Pract. 12, 46.

Sherbourne, C.D., Stewart, A.L., 1991. The MOS social support survey. Soc. Sci. Med. 32 (6), 705-714.

Spycher, B.D., Silverman, M., Brooke, A.M., Minder, C.E., Kuehni, C.E., 2008. Distinguishing phenotypes of childhood wheeze and cough using latent class analysis. Eur. Respir. J. 31, 974-981.

Stansfeld, S.A., 2002. Social support and social cohesion. In: Marmot, M., Wilkinson, R. (Eds.), Social Determinants of Health. Oxford University Press, Oxford, UK, pp. 155-178.

Turner, J., Marino, F., 1994. Social support and social structure: a descriptive epidemiology. J. Health Soc. Behav. 35 (3), $193-212$.

Uchino, B.N., Bowen, K., Carlisle, M., Birmingham, W., 2012. Psychological pathways linking social support to health outcomes: a visit with the "ghosts" of research past, present, and future. Soc. Sci. Med. 74, 949-957.

Uchino, B.N., Cacioppo, J.T., Kiecolt-Glaser, J.K., 1996. The relationship between social support and physiological processes: review with emphasis on underlying mechanisms and implications for health. Psychol. Bull. 119 (3), 488-531. 